University of South Carolina

Scholar Commons

$10-2001$

\title{
Assessing Observation Focus and Conference Targets of Cooperating Teachers
}

Margaret M. Coleman

Illinois State University

Murrary F. Mitchell

University of South Carolina - Columbia, mmitchel@mailbox.sc.edu

Follow this and additional works at: https://scholarcommons.sc.edu/pedu_facpub

Part of the Education Commons

\section{Publication Info}

Published in Journal of Teaching in Physical Education, Volume 20, Issue 1, 2001, pages 40-54.

http://journals.humankinetics.com/jtpe-contents

(C) 2003 by Human Kinetics Publishers, Inc.

This Article is brought to you by the Physical Education, Department of at Scholar Commons. It has been accepted for inclusion in Faculty Publications by an authorized administrator of Scholar Commons. For more information, please contact digres@mailbox.sc.edu. 


\title{
Assessing Observation Focus and Conference Targets of Cooperating Teachers
}

\author{
Margaret M. Coleman \\ Illinois State University \\ Murray Mitchell \\ University of South Carolina
}

\begin{abstract}
The purpose of this study was to develop a strategy to assess two facets of the supervisory responsibilities of Cooperating Teachers (CTs): (a) what CTs choose to observe during a lesson when preparing to offer comments to a student teacher and (b) what CTs choose to bring to the attention of student teachers after observing a lesson. The purpose also was to determine the usefulness of the strategy in discriminating among CTs that may have different preparation backgrounds for supervisory duties. Eighteen elementary level CTs participated by individually watching a videotaped lesson, preparing a written critique, and responding to interviews regarding the supervision of a student teacher, Results support the strategy used as a viable means for identifying selected supervisory abilities of CTs, facilitating the identification of discernible similarities and differences among CTs, and discriminating between two groups of CTs with different backgrounds.
\end{abstract}

The student teaching experience is generally regarded as an integral and required part of the teacher preparation experience. Indeed, student teachers (STs) and their university supervisors single out student teaching as the most valuable experience in professional preparation programs (Conant, 1963; Coulon, 1991; Paese, 1984; Siedentop, 1981; Tannehill \& Zakrajsek, 1988). Paradoxically, little is known about how universities can use this capstone experience to "intensify their programmatic message to trainees" (Dodds, 1989, p. 63). Literature addressing the socialization of teachers indicates that making the student teaching experience at least congruent with the rest of the teacher preparation program is important if programs are to have a positive impact on recruits (Lawson, 1983, 1986).

\section{Student Teaching}

Traditionally, the two individuals who play roles in providing guidance and determining the success of the student teaching experience are the university supervisor and the cooperating teacher (CT). The role of the university supervisor

M. Coleman is with the Department of Health, Physical Education and Recreation at Illinois State University, Normal, IL 61790-5121; M. Mitchell is with the Department of Physical Education at the University of South Carolina, Columbia, SC 29208. 
has been viewed as unnecessary by some (Monson \& Bebb, 1970) and extremely complex and very important by others (Zimpher, DeVoss, \& Nott, 1980). Siedentop (1981) expressed another perspective on the role of university supervisors when he stated the belief that "university supervision, in the form of visitations, is economically and pedagogically inefficient" (p. 33).

The role of the CT, on the other hand, has been described consistently as influential and even essential to the student teaching experience (Copeland, 1980; Dispoto, 1980; Karmos \& Jacko, 1977; Koehler, 1984; Seperson \& Joyce, 1973; Yee, 1969). An important extension of this influence is the finding that the teaching of most STs closely reflects the methods used by their CTs rather than the methods suggested in their teacher preparation programs (Joyce \& Harootunian, 1967; Templin, 1979; Yee, 1969), when these methods are at odds with each other. Locke (1972) portrayed the significance of the influence of cooperating teachers and public schools with the following comment: "The best program in the world can produce trainees with the desired behaviors and values - but any public school that does not share the same values can reshape the trainee in a few days" (p. 99). Clearly, selecting and training CTs who can communicate messages that are consistent with the teacher preparation program matters.

Several authors have identified critical supervision duties, and these are summarized in Table 1. Consistent attention in programs to developing supervisory skills, with some variation, is on providing an effective model for students to see, observing the student teacher in action, identifying salient details of content selection and presentation along with pupil responses, choosing the sequence of topics for attention in a conference, giving feedback on current status, setting goals for future performances, and monitoring progress toward some notion of what a successful beginning teacher should be able to demonstrate.

Selecting CTs is problematic in many disciplines and in most parts of the country. Paese (1984) suggested that "many teachers are selected to be cooperating teachers, not because they are master teachers, but because there is a lack of placements" (p. 51). The selection process for CTs has been described as arbitrary (Turney, 1987) or the result of an expressed interest to serve in such a role (Cochran-Smith, 1991). These descriptions were echoed by Rikard and Veal (1996) when they described the lack of supervisory comfort and expertise of participants in their study. Difficulties in selecting CTs minimizes the chances that a program-

Table 1 A Conceptual Framework for CT Supervisory Duties

\begin{tabular}{lccccc}
\hline Author & Modeling & $\begin{array}{c}\text { Preteach } \\
\text { conference }\end{array}$ & $\begin{array}{c}\text { Observe a } \\
\text { lesson }\end{array}$ & $\begin{array}{c}\text { Postteach } \\
\text { Analyze } \\
\text { data }\end{array}$ & $\begin{array}{c}\text { conference } \\
\text { discuss/set } \\
\text { goals }\end{array}$ \\
\hline Cogan (1973) & $x$ & $x$ & $x$ & $x$ & $x /-$ \\
Coleman, et al (1995) & $x$ & $x$ & & $x$ & $x /-$ \\
Koehler (1986) & $x$ & $x$ & $x$ & $x$ & $x /-$ \\
Metzler (1990) & & $x$ & $x$ & $x$ & $x / x$ \\
Ocansey (1988) & & & & & $x /-$ \\
Tannehill \& & & & $x$ & & $x / x$ \\
Zakrajsek (1990) & & & & &
\end{tabular}


matic message from the undergraduate training program will be carried through to the student teaching experience.

Three concerns are prominent in the use of CTs. One concern involves identifying desirable candidates to become CTs. The second concern involves creating an appropriate training program, once potential CTs have expressed an interest in supervising STs. The third concern involves monitoring the performance of CTs to ensure program congruence.

Identifying good CTs is a major problem for physical education teacher education (PETE) programs. If the CT has the influence on student teaching described in the literature, it is critical that we have a way to select good CTs. Training CTs is a consistent suggestion in studies of supervision and student teaching. Several studies have shown that CTs can be trained to be effective supervisors (Hutslar, 1977; Killian \& McIntyre, 1986; Ocansey, 1988; Tannehill \& Zakrajsek, 1990; Thies-Sprinthall, 1986).

Unfortunately, not all programs have a motivated pool of potential CTs or the resources to offer a full training model. Hence, a simple system to identify the competence and suitability of a CT who might best facilitate the goals of a teacher preparation program is needed. Whether or not programs have the resources to offer supervisory training, a screening mechanism is still warranted when selecting CTs to work with STs. A simple screening strategy could be used to identify CTs who match up well with program goals. Such an assessment strategy could also be used to determine who has mastered key skills after completing a training program or to evaluate the retention of, or proficiency in, important supervisory skills.

The purpose of this study was to develop a strategy to assess two facets of the supervisory responsibilities of CTs: (a) what CTs choose to observe during a lesson when preparing to offer comments to a ST and (b) what CTs would choose to bring to the attention of STs after observing a lesson. It was also the purpose of this study to determine the usefulness of the strategy in discriminating among CTs that may have different preparation backgrounds for supervisory duties. These facets were chosen because there is at least some evidence to suggest that CTs do not observe systematically and that they provide minimal feedback to their STs (Rikard \& Veal, 1996; Tannehill \& Zakrajsek, 1988). Furthermore, when feedback is provided, a primary concern for CTs is often attention to maintaining a positive feeling for the student (Rikard \& Veal, 1996). Hence, CT comments may not be as focused on improvement and consistency with program goals as university-based teacher educators would hope. It should be noted that no attempt was made to assess program effectiveness; rather, one dimension of program congruence was focal.

\section{Methods}

\section{Context}

The CTs from the University of South Carolina (USC) clinical model teacher (CMT) program in Columbia are a relevant portion of this study, and, therefore, the program warrants some description. Briefly, the program has been operating for over 10 years, and potential CMTs must meet two requirements. First, prospective CMTs must demonstrate excellence in teaching as judged by the teacher 
preparation faculty. Excellence is documented through videotaped lessons and personal observations by one or more faculty members.

The second requirement involves the successful completion of two master's level courses in the teacher preparation program. One course deals with the supervisory process and techniques of systematic observation and is designed specifically to train clinical teachers. The second course deals with the theoretical and functional foundations of effective teaching.

The supervision course addresses ST characteristics and departmental expectations for STs and CMTs. The course requires proficiency in collecting objective data and developing personal interaction skills for monitoring and providing support and feedback to a ST.

The effective teaching course is designed to acquaint prospective CMTs with the language, procedures, and instructional practices that are central in the teacher preparation program. For example, specific terminology is used throughout the three methods-course sequence that leads up to student teaching. Learning this terminology allows the ST and CMT to communicate clearly with regard to lesson plan format, lesson structure, task sequencing, and presentation. As a result, clarity of instructional performance feedback is enhanced.

The role of the university supervisor in this program is minimal and is restricted only to that prescribed by state law. During the student teaching placement, CMTs maintain systematic observational data on STs and model effective teaching strategies. A major responsibility given to the CMTs is that of evaluation. The CMT completes a midterm report at the halfway point of the ST placement to alert the university and the ST to areas in need of improvement. The CMT also completes a final evaluation of the ST including the assignment of a final letter grade for the placement. Since each ST has two placements (leading to K12 certification), the letter grades from each placement are averaged to arrive at a final grade for student teaching.

The CMT is responsible for meeting with the ST as necessary to discuss results of observation data. Thus, the timing of conferences is not predetermined. Rather, formal and informal conferences are held when either the ST or CMT see a need. Conferences are self-paced to capitalize on "teachable moments" and specific concerns from classes that have just occurred. The CMTs have "adjunct faculty" status at USC and receive a nominal stipend for the semester.

The CTs who comprise the Other Cooperating Teachers (OCTs) group are affiliated with two other universities, each with accredited elementary teacher preparation programs in physical education and both located in South Carolina. CTs for both schools are drawn from area teachers who are willing to supervise STs. Neither of the schools requires graduate course work from their CTs, and the responsibility of assigning grades to STs remains with the universities.

\section{Participants}

A total of 18 CTs who actively supervise STs in physical education at the elementary level in South Carolina were participants. Nine participants were part of the CMT Program at USC in Columbia and were selected randomly from a list of elementary CMTs. Nine other CTs from two additional universities were designated as other cooperating teachers (OCTs). The OCTs were selected from a pool of teachers who work with STs at the elementary level. University supervi- 
sors provided a list of all active CTs who had supervised within the last 4 years. Combining the lists resulted in a pool of 11 OCTs with 9 of them agreeing to participate in the study.

The OCT and CMT groups were similar in age and gender makeup. The average age of the OCT group was 39; the CMTs, 40 . The OCT group was comprised of 2 men and 7 women, while the CMT group had 3 men and 6 women. Regarding awards, 5 CMTs and 4 OCTs had earned teacher of the year awards, each group had one participant whose school had been awarded model school status, and both groups had accumulated a variety of other minor awards. Members of the OCT group ranged from 6 to 26 years of teaching experience, while the CMT group had from 9 to 26 years of teaching experience, and all 18 had experience teaching basketball, which was the focus of the lesson observed. Last, the OCT group had an average of 7 years of supervisory experience, and the CMTs had an average of 9 years of supervisory experience.

The educational backgrounds of participants differed slightly. While 6 of the 9 CMTs all went to the same undergraduate university (USC), the OCTs went to 7 different undergraduate schools. All 9 of the CMTs had either completed or were working toward a graduate degree at USC. In contrast, 7 of the 9 OCTs had graduate degrees from 4 different institutions, and 2 participants were not working toward any graduate degree.

\section{The Assessment Protocol}

Each participant individually watched a videotaped lesson taught by a ST. Specific contextual information was provided to the participants with background information about the lesson and teacher. Participants were asked to prepare a written critique of the lesson that was as complete and thorough as possible. They were also told that they would be interviewed as to how they would supervise this ST.

Lesson. The videotaped lesson was the first day of a unit on basketball for an actual fourth grade class taught by a real ST. Participants were told that what was shown was representative of consistent and prevalent behavior on the part of the ST at the elementary school placement.

The lesson occurred in a multipurpose room with 19 fourth grade pupils. After a brief introduction by the teacher, pupils were taken through a series of tasks in a direct instruction, command style. Each pupil worked with a ball (some basketballs and some soccer balls), while the teacher provided a series of refinements for dribbling with the right hand, left hand, and switching hands - all without allowing students to move from their assigned position in the room.

Pupils then moved to partner tasks for the chest pass, bounce pass, and combinations of dribbling in a stationary position with a pass to their partner. The lesson ended with about a 2-min closure in which the teacher summarized and questioned pupils regarding the key tasks and cues of the lesson with a brief introduction of the content for their next class in this unit.

Pupils were engaged in physical activity for approximately $36 \%$ of the lesson with teacher instruction taking approximately $53 \%$ of the lesson. Remaining time was minimally taken with transitions and waiting. The teacher circulated throughout the entire instructional space, staying on the perimeter with most of the class in his view at all times. The camera angle allowed most pupils to be viewed throughout the 40-min lesson. 
Viewing of lesson. Participants viewed the videotaped lesson on a combination videocassette player and monitor that automatically displayed the time elapsed in the lesson. Participants were given the remote control and reminded that they could stop the tape at any time to ask questions or get clarification of anything seen or heard on the tape. The ST's comments that are audible to participants are consistent with what an observing CT would be able to hear if watching the lesson from the side.

Writing the critique. Participants were asked to bring materials that they would normally use when observing a ST. They were asked to prepare a written critique of strengths and weaknesses, and to subsequently discuss what they saw and how they would supervise this ST.

Postviewing interview. In an interview that was audiotaped and transcribed for subsequent analysis, participants were asked to choose and prioritize comments from their written critique that they would want to verbalize to the ST after the lesson. Participants were probed to ascertain why they chose certain comments over others. The interview with CTs was semistructured in that initial questions were common across participants with follow-up questions and probes based on initial responses.

\section{Procedures}

Three primary sources of information were used in this study. First, the written critiques were compared and contrasted. Second, field notes were taken regarding observable approaches to the process of supervision demonstrated by participants. Attention was particularly focused on supervisory materials used and any additional information requested. The third data source came from the transcribed interviews. Responses were analyzed following a form of the constant comparative method (Lincoln \& Guba, 1985) to generate categories of supervisory behavior. Individual comments were extracted from the complete transcripts and sorted until identifiable categories of behavior emerged.

Trustworthiness. An independent coder was informed of the research questions and the methods of data collection. This coder did not know any of the participants being studied and had not seen the lesson. Hence, the coder had no preconceptions regarding the data; however, this coder was a teacher with over 20 years of teaching experience

Coding categories were established, and each transcript was independently coded by the lead author and the independent coder. Consensus was reached on any disagreements. Using a simple calculation of percent of interobserver agreement, coders achieved over $90 \%$ agreement on coding when 2 of the 18 transcripts were reanalyzed. Intracoder reliability reached over $80 \%$ when three transcripts were reanalyzed 5 weeks after initial coding was completed.

The trustworthiness of data collected from participants was also examined from a second perspective. Confirmation interviews were held with present and former STs and colleagues of participants to ask them to recall the supervisory approaches used by participants in this study. Insights gained from these sources were used to confirm or refute the accuracy and validity of the information reported by participants. Lincoln and Guba (1985) describe this as a "reconstruction interview" (p. 268) and a viable approach to triangulating other data. 


\section{Results}

The purpose of this study was to develop a strategy to assess two facets of the supervisory responsibilities of CTs. It was also the purpose of this study to determine the usefulness of the strategy in discriminating among CTs that may have different preparation backgrounds for supervisory duties. This latter purpose will be used as a mechanism for exploring the viability of the assessment strategy in the presentation of results. First, members of the two different groups will be compared relative to how they prepared for their task, looking at their written critiques and targets for conferencing topics.

\section{Differences Between CMTs and OCTs}

\section{Preparation}

All CMTs had been trained to do systematic observation, and all brought some type of writing material, but only one brought any type of observation instrument. A "Perimeter and Equipment Coding Form" was used by this participant to assess the management skills and an "Extension, Refinement and Application Analysis" form was used to evaluate content development. Over half of the remaining CMTs ( 5 of the 9 ) offered to do an observation form. Indeed, most (6 of the 9) noted that their typical strategy was to take field notes in early lessons and to follow up with any needed observation forms when viewing subsequent lessons.

None of the OCTs discussed using any type of systematic observation that targeted specific skills. However, 2 of the 9 did offer to use a specific tool commonly used to assess beginning teachers in South Carolina at the time of the study, the Assessment of Performance in Teaching (APT; South Carolina Department of Education, 1983). One of these 2 OCTs offered to do an APT or combine the APT with a Program for Effective Teaching (PET) form. The APT and PET forms were tied to a staff development course (Madeline Hunter) in the area of instructional skills developed in 1984, based on one perspective of evaluating teachers (Hunter, 1973). Completion of this course was mandatory for physical education teachers in the state. By 1993, however, the program had largely been phased out.

\section{Written Critique}

Remarks on the written critique of the lesson were coded as being a ST strength or a weakness when the remark was clearly intended as such. Anecdotal remarks or general notes were not coded.

The frequency tally of written statements coded as a ST strength appear in Table 2. The percentages shown in parentheses indicate the proportion of remarks in each category to the total number of remarks. Both OCTs and CMTs attended to aspects of the lesson with the same relative degree of importance (in terms of numbers of comments). Overall, both groups wrote most about instruction followed by management, the ST, and pupils. Within categories, however, some differences emerged.

In the instruction category, OCT remarks centered on content development 
and set induction, while CMTs were most concerned with content development, task presentations, and demonstrations. The management concern attracting most of the attention of OCTs was how the ST managed equipment. The CMT comments about management were equally divided among general management skills, handling equipment and people. Efficient distribution of equipment and the lack of behavior problems in the class were noted as strengths. It was also noted that the ST stayed predominantly to the perimeter of activity space. The final category, pupils, did not attract many comments from either group of CTs.

\section{Table 2 Written Critique Strengths and Weaknesses}

\begin{tabular}{|c|c|c|c|c|c|}
\hline \multirow[b]{2}{*}{ Instructional elements } & & \multicolumn{2}{|c|}{ Strengths } & \multicolumn{2}{|c|}{ Weaknesses } \\
\hline & & OCTs & CMTs & OCTs & CMTs \\
\hline Management & & 4 & 6 & 2 & - \\
\hline Time & & - & - & 2 & 4 \\
\hline Equipment & & 7 & 6 & 2 & 7 \\
\hline Space & & 3 & - & - & - \\
\hline People & & 2 & 6 & 5 & 5 \\
\hline & Subtotal & $16(21 \%)$ & $18(27 \%)$ & $11(17 \%)$ & $16(14 \%)$ \\
\hline
\end{tabular}

Instruction

Set induction

Task presentation

\begin{tabular}{|c|c|c|c|c|c|}
\hline \\
\hline & Set induction & 7 & 4 & 2 & 2 \\
\hline & Task presentation & 5 & 7 & 2 & 9 \\
\hline & Cues & 3 & 1 & 2 & 7 \\
\hline & Demonstrations & 3 & 7 & 2 & 2 \\
\hline & Questioning & - & 2 & 2 & 1 \\
\hline & Content development & 9 & 8 & 7 & 36 \\
\hline & Ability levels & 5 & 4 & 2 & 3 \\
\hline & Feedback & 6 & 2 & 5 & 11 \\
\hline & Evaluation & 1 & - & - & - \\
\hline & Fitness inclusion & - & - & 1 & 1 \\
\hline & Closure & 6 & 4 & 1 & - \\
\hline & Subtotal & $45(58 \%)$ & $39(58 \%)$ & $26(39 \%)$ & $72(62 \%)$ \\
\hline Student & teacher & 2 & - & - & - \\
\hline & Movement & 5 & 5 & 5 & 7 \\
\hline & Discipline & 3 & 3 & 1 & 1 \\
\hline & Speaking skills & 1 & - & 6 & 5 \\
\hline & Demeanor & 1 & - & 7 & 6 \\
\hline & Humor & 1 & 1 & 3 & 2 \\
\hline & Content knowledge & - & - & 1 & - \\
\hline & Monitoring & 1 & - & 3 & 2 \\
\hline & Subtotal & $14(18 \%)$ & $9(13 \%)$ & $26(39 \%)$ & $23(20 \%)$ \\
\hline Pupils & & & & & \\
\hline & Movement & - & - & 3 & 6 \\
\hline & Behavior & 2 & 1 & - & - \\
\hline & Subtotal & $2(3 \%)$ & $1(1 \%)$ & $3(5 \%)$ & $6(5 \%)$ \\
\hline Total nuı & mber of statements & 77 & 67 & 66 & 117 \\
\hline
\end{tabular}

Demonstrations 3

Questioning -

Content development 9

Feedback

Ability levels 5

Evaluation

Fitness inclusion

Closure

\begin{tabular}{|c|c|c|c|c|c|}
\hline \\
\hline & Set induction & 7 & 4 & 2 & 2 \\
\hline & Task presentation & 5 & 7 & 2 & 9 \\
\hline & Cues & 3 & 1 & 2 & 7 \\
\hline & Demonstrations & 3 & 7 & 2 & 2 \\
\hline & Questioning & - & 2 & 2 & 1 \\
\hline & Content development & 9 & 8 & 7 & 36 \\
\hline & Ability levels & 5 & 4 & 2 & 3 \\
\hline & Feedback & 6 & 2 & 5 & 11 \\
\hline & Evaluation & 1 & - & - & - \\
\hline & Fitness inclusion & - & - & 1 & 1 \\
\hline & Closure & 6 & 4 & 1 & - \\
\hline & Subtotal & $45(58 \%)$ & $39(58 \%)$ & $26(39 \%)$ & $72(62 \%)$ \\
\hline Student & teacher & 2 & - & - & - \\
\hline & Movement & 5 & 5 & 5 & 7 \\
\hline & Discipline & 3 & 3 & 1 & 1 \\
\hline & Speaking skills & 1 & - & 6 & 5 \\
\hline & Demeanor & 1 & - & 7 & 6 \\
\hline & Humor & 1 & 1 & 3 & 2 \\
\hline & Content knowledge & - & - & 1 & - \\
\hline & Monitoring & 1 & - & 3 & 2 \\
\hline & Subtotal & $14(18 \%)$ & $9(13 \%)$ & $26(39 \%)$ & $23(20 \%)$ \\
\hline Pupils & & & & & \\
\hline & Movement & - & - & 3 & 6 \\
\hline & Behavior & 2 & 1 & - & - \\
\hline & Subtotal & $2(3 \%)$ & $1(1 \%)$ & $3(5 \%)$ & $6(5 \%)$ \\
\hline Total nuı & mber of statements & 77 & 67 & 66 & 117 \\
\hline
\end{tabular}

Student teacher

Movement

Discipline

Speaking skills

Demeanor

Humor

Content knowledge

Monitoring

\begin{tabular}{|c|c|c|c|c|c|}
\hline \\
\hline & Set induction & 7 & 4 & 2 & 2 \\
\hline & Task presentation & 5 & 7 & 2 & 9 \\
\hline & Cues & 3 & 1 & 2 & 7 \\
\hline & Demonstrations & 3 & 7 & 2 & 2 \\
\hline & Questioning & - & 2 & 2 & 1 \\
\hline & Content development & 9 & 8 & 7 & 36 \\
\hline & Ability levels & 5 & 4 & 2 & 3 \\
\hline & Feedback & 6 & 2 & 5 & 11 \\
\hline & Evaluation & 1 & - & - & - \\
\hline & Fitness inclusion & - & - & 1 & 1 \\
\hline & Closure & 6 & 4 & 1 & - \\
\hline & Subtotal & $45(58 \%)$ & $39(58 \%)$ & $26(39 \%)$ & $72(62 \%)$ \\
\hline Student & teacher & 2 & - & - & - \\
\hline & Movement & 5 & 5 & 5 & 7 \\
\hline & Discipline & 3 & 3 & 1 & 1 \\
\hline & Speaking skills & 1 & - & 6 & 5 \\
\hline & Demeanor & 1 & - & 7 & 6 \\
\hline & Humor & 1 & 1 & 3 & 2 \\
\hline & Content knowledge & - & - & 1 & - \\
\hline & Monitoring & 1 & - & 3 & 2 \\
\hline & Subtotal & $14(18 \%)$ & $9(13 \%)$ & $26(39 \%)$ & $23(20 \%)$ \\
\hline Pupils & & & & & \\
\hline & Movement & - & - & 3 & 6 \\
\hline & Behavior & 2 & 1 & - & - \\
\hline & Subtotal & $2(3 \%)$ & $1(1 \%)$ & $3(5 \%)$ & $6(5 \%)$ \\
\hline Total nuı & mber of statements & 77 & 67 & 66 & 117 \\
\hline
\end{tabular}

\begin{tabular}{|c|c|c|c|c|c|}
\hline \\
\hline & Set induction & 7 & 4 & 2 & 2 \\
\hline & Task presentation & 5 & 7 & 2 & 9 \\
\hline & Cues & 3 & 1 & 2 & 7 \\
\hline & Demonstrations & 3 & 7 & 2 & 2 \\
\hline & Questioning & - & 2 & 2 & 1 \\
\hline & Content development & 9 & 8 & 7 & 36 \\
\hline & Ability levels & 5 & 4 & 2 & 3 \\
\hline & Feedback & 6 & 2 & 5 & 11 \\
\hline & Evaluation & 1 & - & - & - \\
\hline & Fitness inclusion & - & - & 1 & 1 \\
\hline & Closure & 6 & 4 & 1 & - \\
\hline & Subtotal & $45(58 \%)$ & $39(58 \%)$ & $26(39 \%)$ & $72(62 \%)$ \\
\hline Student & teacher & 2 & - & - & - \\
\hline & Movement & 5 & 5 & 5 & 7 \\
\hline & Discipline & 3 & 3 & 1 & 1 \\
\hline & Speaking skills & 1 & - & 6 & 5 \\
\hline & Demeanor & 1 & - & 7 & 6 \\
\hline & Humor & 1 & 1 & 3 & 2 \\
\hline & Content knowledge & - & - & 1 & - \\
\hline & Monitoring & 1 & - & 3 & 2 \\
\hline & Subtotal & $14(18 \%)$ & $9(13 \%)$ & $26(39 \%)$ & $23(20 \%)$ \\
\hline Pupils & & & & & \\
\hline & Movement & - & - & 3 & 6 \\
\hline & Behavior & 2 & 1 & - & - \\
\hline & Subtotal & $2(3 \%)$ & $1(1 \%)$ & $3(5 \%)$ & $6(5 \%)$ \\
\hline Total nuı & mber of statements & 77 & 67 & 66 & 117 \\
\hline
\end{tabular}

\begin{tabular}{|c|c|c|c|c|c|}
\hline \\
\hline & Set induction & 7 & 4 & 2 & 2 \\
\hline & Task presentation & 5 & 7 & 2 & 9 \\
\hline & Cues & 3 & 1 & 2 & 7 \\
\hline & Demonstrations & 3 & 7 & 2 & 2 \\
\hline & Questioning & - & 2 & 2 & 1 \\
\hline & Content development & 9 & 8 & 7 & 36 \\
\hline & Ability levels & 5 & 4 & 2 & 3 \\
\hline & Feedback & 6 & 2 & 5 & 11 \\
\hline & Evaluation & 1 & - & - & - \\
\hline & Fitness inclusion & - & - & 1 & 1 \\
\hline & Closure & 6 & 4 & 1 & - \\
\hline & Subtotal & $45(58 \%)$ & $39(58 \%)$ & $26(39 \%)$ & $72(62 \%)$ \\
\hline Student & teacher & 2 & - & - & - \\
\hline & Movement & 5 & 5 & 5 & 7 \\
\hline & Discipline & 3 & 3 & 1 & 1 \\
\hline & Speaking skills & 1 & - & 6 & 5 \\
\hline & Demeanor & 1 & - & 7 & 6 \\
\hline & Humor & 1 & 1 & 3 & 2 \\
\hline & Content knowledge & - & - & 1 & - \\
\hline & Monitoring & 1 & - & 3 & 2 \\
\hline & Subtotal & $14(18 \%)$ & $9(13 \%)$ & $26(39 \%)$ & $23(20 \%)$ \\
\hline Pupils & & & & & \\
\hline & Movement & - & - & 3 & 6 \\
\hline & Behavior & 2 & 1 & - & - \\
\hline & Subtotal & $2(3 \%)$ & $1(1 \%)$ & $3(5 \%)$ & $6(5 \%)$ \\
\hline Total nuı & mber of statements & 77 & 67 & 66 & 117 \\
\hline
\end{tabular}

\begin{tabular}{|c|c|c|c|c|c|}
\hline \\
\hline & Set induction & 7 & 4 & 2 & 2 \\
\hline & Task presentation & 5 & 7 & 2 & 9 \\
\hline & Cues & 3 & 1 & 2 & 7 \\
\hline & Demonstrations & 3 & 7 & 2 & 2 \\
\hline & Questioning & - & 2 & 2 & 1 \\
\hline & Content development & 9 & 8 & 7 & 36 \\
\hline & Ability levels & 5 & 4 & 2 & 3 \\
\hline & Feedback & 6 & 2 & 5 & 11 \\
\hline & Evaluation & 1 & - & - & - \\
\hline & Fitness inclusion & - & - & 1 & 1 \\
\hline & Closure & 6 & 4 & 1 & - \\
\hline & Subtotal & $45(58 \%)$ & $39(58 \%)$ & $26(39 \%)$ & $72(62 \%)$ \\
\hline Student & teacher & 2 & - & - & - \\
\hline & Movement & 5 & 5 & 5 & 7 \\
\hline & Discipline & 3 & 3 & 1 & 1 \\
\hline & Speaking skills & 1 & - & 6 & 5 \\
\hline & Demeanor & 1 & - & 7 & 6 \\
\hline & Humor & 1 & 1 & 3 & 2 \\
\hline & Content knowledge & - & - & 1 & - \\
\hline & Monitoring & 1 & - & 3 & 2 \\
\hline & Subtotal & $14(18 \%)$ & $9(13 \%)$ & $26(39 \%)$ & $23(20 \%)$ \\
\hline Pupils & & & & & \\
\hline & Movement & - & - & 3 & 6 \\
\hline & Behavior & 2 & 1 & - & - \\
\hline & Subtotal & $2(3 \%)$ & $1(1 \%)$ & $3(5 \%)$ & $6(5 \%)$ \\
\hline Total nuı & mber of statements & 77 & 67 & 66 & 117 \\
\hline
\end{tabular}

1

1
1

\begin{tabular}{|c|c|c|c|c|c|}
\hline \\
\hline & Set induction & 7 & 4 & 2 & 2 \\
\hline & Task presentation & 5 & 7 & 2 & 9 \\
\hline & Cues & 3 & 1 & 2 & 7 \\
\hline & Demonstrations & 3 & 7 & 2 & 2 \\
\hline & Questioning & - & 2 & 2 & 1 \\
\hline & Content development & 9 & 8 & 7 & 36 \\
\hline & Ability levels & 5 & 4 & 2 & 3 \\
\hline & Feedback & 6 & 2 & 5 & 11 \\
\hline & Evaluation & 1 & - & - & - \\
\hline & Fitness inclusion & - & - & 1 & 1 \\
\hline & Closure & 6 & 4 & 1 & - \\
\hline & Subtotal & $45(58 \%)$ & $39(58 \%)$ & $26(39 \%)$ & $72(62 \%)$ \\
\hline Student & teacher & 2 & - & - & - \\
\hline & Movement & 5 & 5 & 5 & 7 \\
\hline & Discipline & 3 & 3 & 1 & 1 \\
\hline & Speaking skills & 1 & - & 6 & 5 \\
\hline & Demeanor & 1 & - & 7 & 6 \\
\hline & Humor & 1 & 1 & 3 & 2 \\
\hline & Content knowledge & - & - & 1 & - \\
\hline & Monitoring & 1 & - & 3 & 2 \\
\hline & Subtotal & $14(18 \%)$ & $9(13 \%)$ & $26(39 \%)$ & $23(20 \%)$ \\
\hline Pupils & & & & & \\
\hline & Movement & - & - & 3 & 6 \\
\hline & Behavior & 2 & 1 & - & - \\
\hline & Subtotal & $2(3 \%)$ & $1(1 \%)$ & $3(5 \%)$ & $6(5 \%)$ \\
\hline Total nuı & mber of statements & 77 & 67 & 66 & 117 \\
\hline
\end{tabular}

\begin{tabular}{|c|c|c|c|c|c|}
\hline \\
\hline & Set induction & 7 & 4 & 2 & 2 \\
\hline & Task presentation & 5 & 7 & 2 & 9 \\
\hline & Cues & 3 & 1 & 2 & 7 \\
\hline & Demonstrations & 3 & 7 & 2 & 2 \\
\hline & Questioning & - & 2 & 2 & 1 \\
\hline & Content development & 9 & 8 & 7 & 36 \\
\hline & Ability levels & 5 & 4 & 2 & 3 \\
\hline & Feedback & 6 & 2 & 5 & 11 \\
\hline & Evaluation & 1 & - & - & - \\
\hline & Fitness inclusion & - & - & 1 & 1 \\
\hline & Closure & 6 & 4 & 1 & - \\
\hline & Subtotal & $45(58 \%)$ & $39(58 \%)$ & $26(39 \%)$ & $72(62 \%)$ \\
\hline Student & teacher & 2 & - & - & - \\
\hline & Movement & 5 & 5 & 5 & 7 \\
\hline & Discipline & 3 & 3 & 1 & 1 \\
\hline & Speaking skills & 1 & - & 6 & 5 \\
\hline & Demeanor & 1 & - & 7 & 6 \\
\hline & Humor & 1 & 1 & 3 & 2 \\
\hline & Content knowledge & - & - & 1 & - \\
\hline & Monitoring & 1 & - & 3 & 2 \\
\hline & Subtotal & $14(18 \%)$ & $9(13 \%)$ & $26(39 \%)$ & $23(20 \%)$ \\
\hline Pupils & & & & & \\
\hline & Movement & - & - & 3 & 6 \\
\hline & Behavior & 2 & 1 & - & - \\
\hline & Subtotal & $2(3 \%)$ & $1(1 \%)$ & $3(5 \%)$ & $6(5 \%)$ \\
\hline Total nuı & mber of statements & 77 & 67 & 66 & 117 \\
\hline
\end{tabular}

\begin{tabular}{|c|c|c|c|c|c|}
\hline \\
\hline & Set induction & 7 & 4 & 2 & 2 \\
\hline & Task presentation & 5 & 7 & 2 & 9 \\
\hline & Cues & 3 & 1 & 2 & 7 \\
\hline & Demonstrations & 3 & 7 & 2 & 2 \\
\hline & Questioning & - & 2 & 2 & 1 \\
\hline & Content development & 9 & 8 & 7 & 36 \\
\hline & Ability levels & 5 & 4 & 2 & 3 \\
\hline & Feedback & 6 & 2 & 5 & 11 \\
\hline & Evaluation & 1 & - & - & - \\
\hline & Fitness inclusion & - & - & 1 & 1 \\
\hline & Closure & 6 & 4 & 1 & - \\
\hline & Subtotal & $45(58 \%)$ & $39(58 \%)$ & $26(39 \%)$ & $72(62 \%)$ \\
\hline Student & teacher & 2 & - & - & - \\
\hline & Movement & 5 & 5 & 5 & 7 \\
\hline & Discipline & 3 & 3 & 1 & 1 \\
\hline & Speaking skills & 1 & - & 6 & 5 \\
\hline & Demeanor & 1 & - & 7 & 6 \\
\hline & Humor & 1 & 1 & 3 & 2 \\
\hline & Content knowledge & - & - & 1 & - \\
\hline & Monitoring & 1 & - & 3 & 2 \\
\hline & Subtotal & $14(18 \%)$ & $9(13 \%)$ & $26(39 \%)$ & $23(20 \%)$ \\
\hline Pupils & & & & & \\
\hline & Movement & - & - & 3 & 6 \\
\hline & Behavior & 2 & 1 & - & - \\
\hline & Subtotal & $2(3 \%)$ & $1(1 \%)$ & $3(5 \%)$ & $6(5 \%)$ \\
\hline Total nuı & mber of statements & 77 & 67 & 66 & 117 \\
\hline
\end{tabular}


The frequency tally of written statements coded as a weakness also appear in Table 2. The percentages shown in parentheses indicate the proportion of remarks in each category to the total number of remarks. Similar to comments on strengths, both groups identified areas of weakness in approximately the same order. For both OCTs and CMTs, instruction and the ST received the most attention. In the category of instruction, OCTs wrote about content development and feedback. Content development was the overwhelming topic of attention for CMTs, with feedback and task presentation also receiving some attention. In the category of instruction, CMTs recorded almost three times the number of comments as OCTs. In the ST category, both CMT and OCT remarks focused on the ST's movement, speaking skills, and demeanor as areas of weakness.

In regard to management, OCTs noted management of people as a weakness while CMTs expressed more concern about equipment. The comments from both groups regarding pupils attended to the lack of movement during the lesson.

\section{Conferencing Targets}

When participants were asked if there were additional strengths or weaknesses to the lesson that they would talk about with the ST in a conference, many more comments were generated. A common strategy for both the CMT and OCT groups was to begin the conference with something positive to put the ST at ease and set a positive tone for the conference. Beyond this positive opening, there were three key areas that would receive attention. Management, a blueprint for the lesson addressing lesson organization and content development, and attention to pupils were the three areas covered to different degrees by both groups.

Management of the lesson was more likely to be viewed as a strength by the OCTs. The CMTs made more prescriptive comments with reference to the management of the lesson, particularly about the management of time, people, space, and equipment.

Most participants wanted to see the lesson taught in a different way than they had seen. OCT comments were more likely to address only presentation of content, whereas CMT comments were more likely to address both content presentation and organization of the lesson.

An emphasis on the organization of the lesson, or blueprint for the lesson, was evident in CMT comments that were fairly consistent across the 9 CMTs. These CMTs wanted to see a definite structure, beginning with a set induction and followed by a variety of task presentations where the content of the class is stressed, and ending with some type of closure. For example,

I would make him come up with some ways of personalizing the lesson with the kids, establishing a rapport and some kind of introduction to the sport of basketball rather than just jumping into it to a specific skill in the sport. Make him think through some ways that he could hook them and lure them in - a good hook in the beginning. (CMT-3).

Task presentations and content development received a great deal of attention from CMTs. As one CMT described her expectations, "Well, I'd just show him the observations and just say, you know, this makes sense but there are no application tasks here and that's something that's going to be real important" (CMT-5). Another CMT described a concern with matching refinements and 
subsequent tasks: "When you take the time to refine, then you want your task to center on that" (CMT-8). For another CMT, the task progressions were simply too fast: "In my opinion, for a first lesson for 4th grade, there was too much too fast; not enough refining, extension" (CMT-2).

OCTs identified lesson organization as a topic that would be included in a conference, but the consistency of comments and language was not present, and there were contradictions to the observations of the CMTs. For example, while matching refining cues to tasks was problematic for CMTs, one OCT thought "his critical elements were good in his instruction" (OCT-3). While set induction was problematic for some of the CMTs, this was less true for OCTs: "So they knew - so it was very clear what they were going to do from the beginning" (OCT6), and "I think he came out and he gave a good overview of what the lesson was going to be like, what the unit's going to be like, what we're going to do in the future" (OCT-8).

Comments regarding pupils focused on both skill development and the affective experience. CMT comments emphasized the skill development of the pupils while OCT comments were divided almost equally between skill development and the affective experience.

Recommendations for future performance. A notable difference was found between the two groups of CTs in the area of future recommendations. Seven of the 9 CMTs had definite future recommendations, while just 2 of the OCTs would have made future recommendations to the ST during a conference. Both OCTs wanted the ST to attend to what the pupils were doing. As one said, "If you see that they're getting it, don't just walk away and go see if there's somebody else that's not-you know, give them something harder to do" (OCT-7)

The majority of the future recommendations made by CMTs involved the lesson plan. For example, "If that's going to be the lesson, I would re-structure the lesson" (CMT-3); "He said at the end, next they're going to start on lay-ups, and I thought, wait a minute now; they didn't move any today-how are they going to start on lay-ups when they didn't have practice dribbling?" (CMT-4). Another CMT expected to see more attention to content development in the lesson with explicit attention to extensions, refinements, and applications: "And then if I see there's a problem, then there's going to have to be written out super-duper detail if we don't have it" (CMT-5). There were also suggestions regarding the quality of demonstrations given prior to assigning tasks to pupils.

\section{Support for Conference Content}

Clear differences were found between groups regarding the data gathering strategies for supporting conference content. CTs were asked what criteria they would use to identify lesson attributes, and when improvements were suggested, how they would assess whether or not the ST had actually made the improvement. OCTs relied heavily on the use of eyeballing and anecdotal recording. When an objective measurement was mentioned, 6 of the 9 OCTs indicated they would use such an instrument just once or not at all in their assessment of the ST.

Engaging the ST through the use of a videotape or an audiotape of his performance was mentioned by only 2 of the OCTs. These CTs also mentioned the possible use of a specific observation tool for the student to guide observations of his own performance. The remaining OCTs were more likely to just watch: "The 
next time I observed him, I would be looking for those things that were negative to see if in my eyes they were positive" (OCT-1).

All 9 CMTs indicated they would use an objective assessment more than once in their evaluation of the ST, and several specific instruments were described. For example, "The perimeter monitoring code would chart his course in the classroom; task presentation instrument is a good one because in that, it lists summary cues" (CMT-3), and "[I would] do another time line; well, generally, when I have time, I do one like three or four times a week" (CMT-6).

\section{Confirmation Interviews}

Participants provided lists of former STs. Of the 9 CMTs, 7 former STs were located and interviewed. Only 4 of the former STs of OCTs could be located and interviewed. Overall, former STs provided solid confirmation for the conferencing behaviors reported by participants. All of the former STs of CMTs recalled the regular use of systematic observation forms. Students of OCTs reported the use of notetaking and observations as strategies used to provide feedback on their performance. No instances of disagreement were found between CT reported strategies and recollections of former STs.

\section{Discussion}

The purpose of this study was to develop a strategy to assess two facets of the supervisory responsibilities of CTs and to determine the usefulness of the strategy in discriminating among CTs with different backgrounds for supervision. Findings on both groups were remarkably similar, an encouraging finding given the intention to select competent CTs.

There were, however, differences between the groups. First, members of both groups demonstrated an awareness of a variety of systematic observation instruments to help guide their observations. While more CMTs were able to identify more specific observation instruments, only one participant actually used an instrument in this study, a finding consistent with previous work by Strand (1992) and Paese (1984). While members of both groups arrived with writing materials, took notes, and attended to the videotape carefully, it is possible that the scenario for the lesson was a factor in this study. That is, if the lesson was described as later in the basketball unit, or if other information about initial problems (i.e., that may have been identified in an earlier visit or in a preobservation conference), CTs may have been more inclined to use specific instruments. For example, would a specific observation tool be used to assess the ST's attempt to decrease management time if the scenario identified this as a goal being addressed?

For future studies, the context of the lesson may need to be revised slightly. Still, in the present form, this scenario did allow participants to discuss their "usual" routine regarding the use of different observation and conferencing strategies. While self-report data must always be viewed with some caution, there is evidence to suggest that these teachers provided accurate information during their Postviewing interviews about their typical performance patterns with STs. As a device for screening potential CTs, these methods at least provide a minimally intrusive way to identify who might best facilitate the goals of a PETE program. 
The profile of comments regarding strengths in the lesson is consistent across both groups. For both groups, the fewest comments were directed to pupils or their responses to assigned tasks. There is a slight edge to OCTs offering more comments on strengths. In combination with total numbers of strengths (OCT, 77; CMT, 67) and weaknesses (OCT, 66; CMT, 117), these findings support the work of Rikard and Veal (1996). In that study, CTs who did provide feedback tended to be most attentive to being positive.

The profile of comments addressing weaknesses in instruction was the main source of difference between groups of participants. Specifically, content development was a central focus of CMTs, who indicated a lesson's content should be comprised of a variety of extension tasks, which are refined as necessary, and should include some type of application task. CMTs suggested refinements that matched cues given in the lesson and several examples of possible extension tasks that could have been included. This focus on how a lesson should proceed and how tasks should be arranged and taught was clearly a priority for CMTs, an emphasis consistent with the USC preservice program.

There was also a notable difference regarding recommendations for the future. CMTs were more prescriptive than OCTs. The most common suggestions involved restructuring the lesson plan and adding specific teaching techniques. These suggestions are consistent with the training program completed by the CMTs and reflect a structured, developmental perspective in guiding the experiences of STs. Preparing STs for future encounters is similar to the goal-setting attribute of most Clinical Supervision Models (Cogan,1973; Ocansey, 1988; Turney, 1987).

The type of language used by CMTs was quite consistent. There was clear evidence of what was described, first by Lortie (1975) and later Lawson (1983), as a shared technical culture. The lack of such a culture in teacher preparation has been lamented as being at least partially responsible for the low impact of teacher education programs, more often characterized by the conflicting views and language systems held by teacher educators. The CMTs in this study exhibited a language system that was consistent with the conceptual framework for teaching that undergirds the courses taken in preparation for assuming the role of a clinical model teacher.

There are at least two key benefits of a shared technical culture between STs and CTs. First, there is potential for greater clarity regarding what will be expected for success, beyond merely using similar names for things. There is also a shared understanding for what is important and how to accomplish these goals. A second benefit is in the increased potential for PETE programs to have an impact on the professional attitudes and behaviors of recruits. Consistent messages from the theory classrooms on campus to the applied activities in the schools are far more powerful than contradictory messages from these two aspects of certification programs.

\section{Conclusions and Implications}

Student teaching is the capstone experience leading to certification, and CTs are key participants in this important event. Consequently, teacher preparation programs are dependent upon CTs who are able to help STs make the transition from being a student to becoming a teacher, and more effective programs send congruent messages. The potential value of the system presented in this 
study is for a minimally intrusive strategy to determine the extent of congruence between a program philosophy and the skills and techniques of prospective (or continuing) CTs.

Based on the findings from this study, three conclusions seem warranted. First, the methods described in this study provide a viable means for identifying selected supervisory techniques in prospective and/or practicing CTs-focus of observation and conference topics. There is potential here for future applications of these methods to selecting and monitoring CTs.

Second, this study facilitated the identification of discernible similarities within one group and differences between the two groups of purposefully selected participants. Researchers seeking a test of the viability of a training program may be interested in the methods piloted in this study. One possible application would be to compare CT's who have had supervisory training with those who have not. This alternative may be more desirable than exposing STs and their pupils to experimental conditions and having to wait through a semester for results.

Third, the CMT group performed in a fashion consistent with the philosophical orientation of the program with which they are associated. The CMTs provided clear targets for corrections, explicit rationales for these comments, and more prescriptive comments for future remediation, and they described a variety of appropriate systematic observation tools that could be used. Put differently, there is an apparent and lasting impact of the USC CMT training program. This conclusion is important to other teacher educators who may want to design ways to influence the practice of CTs as they create placements for their STs. At least two questions remain: (a) are there unobtrusive ways to assess other supervisory duties such as interactive conferencing strategies, and (b) how much training is required to adequately prepare quality CTs? An attempt has been made to learn more about selected supervisory behaviors. As long as student teaching remains a key part of teacher preparation programs, this culminating practicum should continue to draw attention to make the experience more productive for STs, more rewarding for CTs, and a more effective part of teacher preparation programs.

\section{References}

Cochran-Smith, M. (1991). Reinventing student teaching. Journal of Teacher Education, 42, 104-118.

Cogan, M.L. (1973). Clinical supervision. Boston: Houghton Mifflin.

Coleman, M., Mitchell, M., \& Graham, K. (1995, October). A clinical model approach to student teacher supervision. Poster presented at the National Association for Sport and Physical Education conference on Teacher Education, Morgantown, WV.

Conant, J.B. (1963). The education of American teachers. New York: McGraw Hill.

Copeland, W.D. (1980). Affective dispositions of teachers in training toward examples of supervisory behavior. Journal of Educational Research, 74, 37-42.

Coulon, S.C. (1991). The relationship between physical education teacher education program goals and cooperating teacher feedback and task statements. The Physical Educator, 48, 66-71.

Dispoto, R. (1980). Affective changes associated with student teaching. College Student Journal, 14, 190-194. 
Dodds, P. (1989). Trainees, field experiences, and socialization into teaching. In T.J. Templin \& P.G. Schempp (Eds.), Learning to teach (pp. 81-104). Indianapolis, IN: Benchmark Press.

Hunter, M.C. (1973). Appraising teaching performance: One approach. National Elementary Principal, 52(5), 60-62.

Hutslar, S.E. (1977). The effects of training cooperating teachers in applied behavior analysis on student-teaching behavior in physical education. Dissertation Abstracts Service, 37, 4956-A.

Joyce, B.R., \& Harootunian, B. (1967). The structure of teaching. Chicago, IL: Science Research Associates.

Karmos, A.H., \& Jacko, C.M. (1977). The role of significant others during the student teaching experience. Journal of Teacher Education, 28(5), 51-55.

Killian, J.E., \& McIntyre, D.J. (1986), Quality in the early field experiences: A product of grade level and cooperating teachers' training. Teaching and Teacher Education, 2, 367-376.

Koehler, V. (1984, April). University supervision of student teaching. (National Institute of Education Report No. 9061). Austin, TX: University of Texas, R\&D Center for Teacher Education. (Eric Document Reproduction Service No. ED 270 439).

Koehler, V. (1986, April). The instructional supervision of student teachers. Paper presented at the annual meeting of the American Educational Research Association. San Francisco. (ERIC Document Reproduction Service No. ED 271430 ).

Lawson, H.A. (1983). Toward a model of teacher socialization in physical education: The subjective warrant, recruitment, and teacher education (Part 1). Journal of Teaching in Physical Education, 2(3), 3-16.

Lawson, H.A. (1986). Occupational socialization and the design of teacher education programs. Journal of Teaching in Physical Education, 5, 107-116.

Lincoln, Y., \& Guba, E. (1985). Naturalistic inquiry. Beverly Hills, CA: Sage.

Locke, L. (1972). Teacher education: One minute to midnight. AAHPER Proceedings of the National Conference on Professional Preparation of the Elementary Specialist. Lake Ozark, MO.

Lortie, D. (1975). Schoolteacher: A sociological study. Chicago: University of Chicago Press.

Metzler, M. (1990). Instructional supervision for physical education. Champaign, IL: Human Kinetics.

Monson, J.A., \& Bebb, A.M. (1970). New roles for the supervisor of student teaching. Educational Leadership, 28, 44-47.

Ocansey, R. (1988). The effects of a behavioral model of supervision on the supervisory behaviors of cooperating teachers. Journal of Teaching in Physical Education, 8 , 46-63.

Paese, P.C. (1984). The effects of cooperating teacher intervention and a self-assessment technique on the verbal interactions of elementary student teachers. Journal of Teaching in Physical Education, 3(3), 51-58.

Rikard, G.L., \& Veal, M.L. (1996). Cooperating teachers: Insight into their preparation, beliefs, and practices. Journal of Teaching in Physical Education, 15, 279-296.

Seperson, M.A., \& Joyce, B. (1973). Teaching styles of student teachers as related to those of their cooperating teachers. Educational Leadership Research Supplement, 31, 146-151.

Siedentop, D. (1981). The Ohio State University supervision research program summary report. Journal of Teaching in Physical Education, Introductory Issue, 30-38. 
South Carolina Department of Education. (1983). Assessments of performance in teaching. Columbia, SC: Author.

Strand, B.N. (1992). A descriptive profile of teacher preparation practices in physical education teacher education. The Physical Educator, 49, 104-112.

Tannehill, D., \& Zakrajsek, D. (1988). What's happening in supervision of student teachers in secondary physical education. Journal of Teaching in Physical Education, 8, $1-12$.

Tannehill, D., \& Zakrajsek, D. (1990). Effects of a self-directed training program on cooperating teacher behavior. Journal of Teaching in Physical Education, 9, 140-151.

Templin, T.J. (1979). Occupational socialization and the physical education student teacher. Research Quarterly, 50, 482-493.

Thies-Sprinthall, L. (1986). A collaborative approach for mentor training: A working model. Journal of Teacher Education, 37(6), 13-20.

Turney, C. (1987). Supervision of the practicum. In M.J. Dunkin (Ed.), International encyclopedia of teaching and teacher education (pp. 686-695). New York: Pergamon.

Yee, A. (1969). Do cooperating teachers influence the attitudes of student teachers? Journal of Educational Psychology, 60, 327-332.

Zimpher, N.L., DeVoss, G.G., \& Nott, D.L. (1980). A closer look at university student teacher supervision. Journal of Teacher Education, 31, 11-15.

\section{Acknowledgment}

The authors would like to thank Judith Rink for her helpful and insightful comments on earlier drafts of the manuscript. 